\title{
Grão de soja ardido, queimado e fermentado: Alterações das frações proteicas, lipídicas e compostos fenólicos e suas consequências na dieta animal
}

\author{
Burnt, blazed and fermented soybeans: Changes in protein, lipid and phenolic compounds and
}

their consequences in the animal diet

Soja ardido, quemada y fermentada: Cambios en proteínas, lípidos y compuestos fenólicos y sus

consecuencias en la dieta animal

Recebido: 01/02/2021 | Revisado: 07/02/2021 | Aceito: 09/02/2021 | Publicado: 17/02/2021

Guilherme Soares Wenneck

ORCID: https://orcid.org/0000-0003-1014-916X

Universidade Estadual de Maringá, Brasil

E-mail: guilhermesoareswenneck@gmail.com

Gustavo Soares Wenneck

ORCID: https://orcid.org/0000-0002-4151-2358

Universidade Estadual de Maringá, Brasil

E-mail: gustavowenneck@gmail.com

Reni Saath

ORCID: https://orcid.org/0000-0002-6610-2873

Universidade Estadual de Maringá, Brasil E-mail: rsaath@uem.br

Camila de Souza Volpato

ORCID: https://orcid.org/0000-0003-3275-618X Universidade Estadual de Maringá, Brasil E-mail: camila16volpato@gmail.com

Larissa Leite de Araújo

ORCID: https://orcid.org/0000-0003-3882-0453 Universidade Estadual de Maringá, Brasil

E-mail: larissa_leite_araujo@hotmail.com

Nathália de Oliveira Sá

ORCID: https://orcid.org/0000-0003-2796-702X Universidade Estadual de Maringá, Brasil

E-mail: ndeoliveirasa@gmail.com

\begin{abstract}
Resumo
Permanecer no topo como um dos maiores produtores e exportadores de carne do mundo requer alimentos de alto valor proteico e enérgico. Neste contexto, o Brasil é privilegiado já que, mundialmente, é um dos maiores produtores de soja, cujo grão detém alto valor comercial e nutricional, destinado ao consumo humano, extração de óleo e ração animal. Entretanto, a qualidade de seus subprodutos é reflexo da integridade do grão em toda cadeia produtiva: produção, colheita, secagem, armazenamento, industrialização e processamento. Desta forma, em razão da ameaça a qualidade da alimentação animal, resultantes das etapas de pós-colheita, e levando em consideração os paramentos legislativos referentes à classificação qualitativas, foram analisadas as alterações das frações proteicas, lipídicas e compostos fenólicos em grãos de soja fermentado, ardido e queimado. Em decorrência dos defeitos há menores teores de proteína bruta, lipídios e solubilidade proteica, essenciais para formação de proteína animal, e maiores valores de compostos fenólicos. Essas substâncias, promovem complexação com tripsina e quimotripsina, secretadas pelo pâncreas, impedindo sua ação proteolítica, resultando em sobrecarga. Por conseguinte, ocorre hipertrofia do órgão, além reduzir a digestão do restante dos alimentos presente na luz intestinal. Os grãos ardidos, queimados e fermentados, apresentam características indesejáveis na indústria de ração animal, primordialmente, em função de seu baixo teor de proteína e lipídio. Grãos queimados ardidos e fermentados não são recomendados na nutrição animal.
\end{abstract}

Palavras-chave: Glycine max; Nutrição animal; Pós-colheita.

\section{Abstract}

Staying on top as one of the world's largest meat producers and exporters requires high-protein, high-energy foods. In this context, Brazil is privileged since, worldwide, it is one of the largest soy producers, whose grain has high commercial and nutritional value, destined for human consumption, oil extraction and animal feed. However, the quality of its by-products is a reflection of the integrity of the grain and of the entire production chain: production, harvest, drying, storage, industrialization and processing. Thus, due to the threat to the quality of animal feed, 
resulting from the post-harvest stages, and taking into account the legislative standards regarding qualitative classification, changes in protein, lipid and phenolic fractions in fermented soybeans were analyzed, blazed and burnt. Due to the defects, there are lower levels of crude protein, lipids and protein solubility, essences for animal protein formation, and higher values of phenolic compounds. These substances promote complexion with trypsin and chymotrypsin, secreted by the pancreas, preventing their photolytic action, resulting in overload. Consequently, hypertrophy of the organ occurs, in addition to reducing the digestion of the rest of the food present in the intestinal lumen. Blazed, burned and fermented grains have undesirable characteristics in the animal feed industry, primarily due to their low protein and lipid content. Burnt grains, in particular, not recommended for use in animal nutrition, as result of protein denaturation.

Keywords: Glycine max; Animal nutrition; Post-harvest.

\section{Resumen}

Mantenerse en la cima como uno de los mayores productores y exportadores de carne del mundo requiere alimentos ricos en proteínas y energéticos. En este contexto, Brasil es privilegiado ya que, a nivel mundial, es uno de los mayores productores de soja, cuyo grano tiene alto valor comercial y nutricional, destinado al consumo humano, extracción de aceite y alimentación animal. Sin embargo, la calidad de sus subproductos refleja la integridad del grano en toda la cadena productiva: producción, cosecha, secado, almacenamiento, industrialización y procesamiento. Así, debido a la amenaza a la calidad de la alimentación animal, resultante de las etapas de pos cosecha, y teniendo en cuenta la normativa legislativa en materia de clasificación cualitativa, se analizaron los cambios en las fracciones de proteínas, lípidos y fenólicos en la soja fermentada. quemado. Como resultado de los defectos hay niveles más bajos de proteína cruda, lípidos y solubilidad proteica, esenciales para la formación de proteína animal, y valores más altos de compuestos fenólicos. Estas sustancias promueven la complejación con tripsina y quimotripsina, secretadas por el páncreas, impidiendo su acción proteolítica, lo que resulta en sobrecarga. En consecuencia, se produce una hipertrofia del órgano, además de reducir la digestión del resto de alimentos presentes en la luz intestinal. Los granos quemados, quemados y fermentados tienen características indeseables en la industria de la alimentación animal, principalmente debido a su bajo contenido de proteínas y lípidos. Los granos quemados, quemados y fermentados no se recomiendan en la nutrición animal.

Palabras clave: Glycine max; Nutrición animal; Pos cosecha.

\section{Introdução}

O rebanho brasileiro apresenta um efetivo de aproximadamente 213.523.066 de bovinos, 1.390.000 de bubalinos, 5.751.798 de equinos, 5.751.798 de suínos, 10.696.664 de caprinos, 18.948.934 de ovinos e 1.468.351.527 de galináceos, o Brasil apresenta números expressivos sustentados pela alimentação, genética, manejo e saúde animal (IBGE, 2020). Na cadeia operacional, a indústria de alimentação animal tem demonstrado competência e grandiosidade, com uma produção anual de cerca de 75 milhões de toneladas de ração, destinados principalmente à avicultura e suinocultura (EMBRAPA, 2020). Neste contexto, destaca-se a participação da soja, na forma de farelo, como matéria prima essencial na formulação de rações, méritos de seu alto teor proteico e energético, com uma produção anual em torno de 17 milhões de toneladas (EMBRAPA, 2020).

Entretanto, a inclusão deste ingrediente proteico na dieta animal apresenta limitações em razão dos fatores antinutricionais, inibidores de proteases, proteínas alergênicas e saponinas, os quais prejudicam a atividade enzimática comprometendo a digestibilidade e absorção dos nutrientes (Menezes et al., 2017). Em consequência a esses fatores, sua utilização é dependente de processamento térmico (Souza et al., 2019).

Desta maneira, a obrigatoriedade de processamento motivou o desenvolvimento de métodos, como extrusão e tostagem, eficazes na inativação dos fatores antinutricionais e na conservação da qualidade (Stech, 2019). Assim, os valores qualitativos são fruto da cadeia de produção, resultantes das condições climáticas, manejo e ataque de pragas, do processamento e armazenamento (Ramos, 2019). Desta forma, torna-se indispensável à abordagem das propriedades intrínsecas e extrínsecas do grão, bem como, as condições de pós-colheita os quais são submetidos, devendo ter controle criterioso durante o armazenamento, primordialmente quanto à umidade do ar, teor de impurezas, umidade dos grãos e temperatura do ar, já que a qualidade dos grãos não pode ser melhorada, apenas conservada (Ziegler et al., 2016).

Assim, o comprometimento na pós-colheita resultam em defeitos nos grãos, sendo eles leves, como os fermentados e graves como os queimados e ardidos, constituindo um risco na formulação de rações, já que a danificação potencializa a 
presença de microtoxinas, peróxidos, aldeídos e cetonas, além de reduzir seu valor nutricional, sendo provenientes da degradação metabólica (Ramos, 2019). Por isso, esse estudo tem como objetivo analisar os defeitos do grão de soja em função dos valores proteicos, lipídicas e compostos fenólicos e seus efeitos na dieta animal.

\section{Metodologia}

O estudo foi desenvolvido por meio de revisão bibliográfica em periódicos indexados nas principais bases cientificas e livros técnicos na área da medicina veterinária. Analisou-se a dinâmica das etapas pré-colheita, colheita e pós-colheita na produção da soja sobre relacionadas as características da qualidade comercial, e principalmente sobre as características nutricionais considerando sua utilização em dietas animais.

\section{Resultados e Discussão}

\subsection{Qualidade de grãos de soja na colheita e pós-colheita}

A integridade física e qualitativa dos grãos é relacionada à manejos no processo produtivo e características no armazenamento do produto. A presença de grãos avariados, de qualidade físico-química reduzida em função ação de patógenos e processos fermentativos, reduz a qualidade comercial e valor do produto (Hirakuri et al., 2018).

À campo, o desenvolvimento de fungos, como Fusarium verticilioides, F. graminearum, Gibberella zeae, Diplodia maydis, Diplodia macrospora, e espécies dos gêneros Aspergillus, Cephalosporium e Penicillium são comuns (Mendes et al., 2012; Santin et al., 2004, Santin et al., 2009), podendo ser favorecidos por condições ambientais e práticas agrícolas, como a irrigação e atraso na colheita (Pinto et al., 2017).

$\mathrm{O}$ armazenamento, quando adequado, permite manter a qualidade físico-química do produto no tempo, porém o manejo da massa de grãos é dependendo das características iniciais. A presença de patógenos associado a respiração da massa de grãos e alterações nas características do ar, temperatura e umidade relativa, favorece o desenvolvimento de organismos capazes de reduz a qualidade do lote durante o armazenamento (Dürks et al., 2019).

Por consequência, as alterações na aparência dos grãos em função dos defeitos, são refletidos sobre características qualitativas de seus subprodutos, principalmente, destinados a alimentação animal, extração de óleo e em menor escala como alternativa energética (Silva et al., 2019). Logo, efeitos negativos decorrentes da presença de defeitos e fungos têm reflexos nos índices nutricionais do produto e podem determinar a lucratividade na cadeia dos grãos e a diminuição do rendimento alimentar dos animais.

\subsection{Fatores antinutricionais e compostos fenólicos}

Embora possua inúmeras qualidades, a soja apresenta compostos que atuam como proteção natural da planta, e que limitam a utilização in natura pelos ruminantes (Souza et al., 2019). Estes compostos são denominados de fatores antinutricionais e podem interferir no aproveitamento das proteínas e dos demais nutrientes das dietas pelo animal, além de desencadear efeitos fisiológicos não desejados, resultando em inibição de crescimento, hipoglicemia, flatulência ou danos a tecidos como pâncreas e fígado (Souza et al., 2019).

Dentre os fatores antinutricionais, destacam-se as substâncias alergênicas e proteínas antigênicas, as quais atuam inibindo enzimas digestivas, como as proteolíticas (tripsina, quimiotripsina) e amilolítica (amilase) produzidas pelo pâncreas. Os inibidores de proteases presentes na soja são constituídos pelo inibidor de tripsina e quimotripsina "Bowman-Birk" inibidor de tripsina "Kunitz" (Menezes et al., 2017).

Entre os vários efeitos fisiológicos atribuídos aos fatores antitrípsicos destacam-se a complexação com a tripsina e a quimotripsina secretada pelo pâncreas, impedindo a ação proteolítica dessas enzimas (Prete, 2019). Desta maneira, afim de 
compensar a diminuição da ação das enzimas proteolíticas, o pâncreas secreta mais enzimas, que por sua vez, são novamente inibidas, gerando uma sobrecarga pancreática, e consequentemente, uma hipertrofia desse órgão, reduzindo a ação digestiva em todo alimento presente na luz intestinal e, por conseguinte, prejudicando o desempenho desses animais (Kozloski, 2017). A hipertrofia pancreática provoca aumento na produção de enzimas. Desta forma, agravando o quadro nutricional devido à maior mobilização de aminoácidos, uma vez que, para síntese das enzimas tripsina e quimotripsina necessita-se aminoácidos sulfurados (Lima Júnior et al, 2010).

Os compostos fenólicos caracterizam-se como fatores antinutricionais, sendo provenientes do metabolismo especializado da planta, fundamentais nos processos fisiológicos, primordialmente no crescimento, reprodução e defesa contra agentes externos, como fungos (Freiria et al., 2020). Além disso, podem ser formados quando ocorre comprometimento dos manejos sanitário, como na presença de fungos que possuem a enzima fenilalanina amônia-liase, capazes de sintetizar compostos fenólicos, e processamento, englobando: temperatura, umidade, incidência de radiação e integridade da estrutura do grão, podendo ser ocasionados durante a colheita ou pós-colheita (Alves et al., 2017).

Do ponto de vista imunológico, os compostos fenólicos apresentam propriedades antioxidantes e anti-inflamatórias, tendo caráter preventivo frente a patologias e atuando na redução da oxidação lipídica em tecidos (Japiassu, 2018). Entretanto, quando os níveis se encontram acentuados, figura-se como um grão de qualidade baixa, fruto de anomalia na cadeia operacional e principalmente no processamento, infligindo diretamente no valor proteico e energético, bem como na digestibilidade da fibra (Rasera \& Castro, 2020).

O ácido vanílico é o principal representante dos compostos fenólicos no grão da soja. De acordo com Ziegler et al. (2016), em grãos armazenados com $12 \%$ de umidade a $32{ }^{\circ} \mathrm{C}$ houve aumento do teor de ácido vanílico, sendo resultado dos processos de deterioração. Além disso, Dueñas et al. (2012), constatou que a fermentação com Rhyzopus oryzae por 48 horas a $30^{\circ} \mathrm{C}$, eleva os níveis de Ácido Vanílico. Grãos queimados apresentam maiores teores de Ácido Vanílico, Ácido Siríngico, Ácido Ferúlico, Kaempferol e Apigenina e menores de Ácido Clorogênico e Epicatequina. Já grãos ardidos, apresentam elevados teores de Ácido p-cumárico. Ademais, não foram detectados Rutina, Ácido Elágico, Quercetina e Pinocembrina em nenhum dos grãos com alterações, inclusive nos sadios, assim como, catequina, Miricetina e Galangina ficaram abaixo do limite de quantificação (Ramos, 2019).

\subsection{Lipídios}

Principal reservatório de energia e combustível celular, os lipídios são essenciais na inclusão da dieta animal, já que além de fonte energética, interferem significativamente nos valores nutricionais e palatabilidade dos alimentos (Monteiro, 2019). Ainda, os lipídios na alimentação de ruminantes, principalmente em confinamento, potencializam a absorção de vitaminas lipossolúveis e fornece ácidos graxos, conferindo melhores condições para desempenho das funções fisiológicas e rendimento de carcaça. Assim, a inclusão é essencial, sendo o grão de soja, a principal fonte lipoproteica disponível no mercado (Müller, 2018).

Entretanto, o teor de lipídios do estado do grão pode variar significativamente de acordo com as condições do grão de soja. De acordo com Ramos (2019), grãos sadios apresentam em torno de 24,62\% de lipídios; fermentado 26,20\%; ardido $22,15 \%$; queimado $21,85 \%$. Esta oscilação coloca em risco a formulação de ração, uma vez que não são realizadas mensurações com frequências se baseando em valores estipulados em grãos sadios. Desta forma, a utilização de grão com baixo teor de lipídios, como verificado em grãos ardido e queimado, pode comprometer o nível de ingestão e funções fisiológicas, bem como ganho de peso diário (Monteiro, 2019). A redução no teor de lipídios está associada à ação de enzimas lípases e reações bioquímicas em consequência a formação de compostos voláteis (Wrigley et al., 2016).

Em contrapartida, o alto teor de lipídios, presente em grãos fermentados, também pode se comportar como 
prejudicial, devido à influência na digestibilidade da fibra no rúmen. Sendo este fato resultado da ação dos ácidos graxos insaturados sobre os microrganismos ruminais responsáveis pela degradação da fibra, impedindo sua atividade e caminhando para um quadro de intoxicação (Kozloski, 2017). Ademais, o fornecimento de grãos quebrados permite acesso direto a toda à fração lipídica do grão pelos microrganismos, sendo desfavorável como citado anteriormente, oposto do que ocorre quando o grão é fornecido, onde ocorre liberação gradativa dos ácidos graxos (Müller, 2018).

\subsection{Proteína Bruta}

O grão de soja apresenta, aproximadamente, em sua composição básica $40 \%$ de proteína bruta, conferindo-o destaque na nutrição animal sob os demais cereais e algumas leguminosas (Mateus et al., 2018). As proteínas, nutrientes orgânicos nitrogenados são os principais constituintes do organismo do animal, indispensável para o crescimento, produção e reprodução (Mateus et al., 2018). Possuem ampla funcionalidade, sendo elas: estrutural, na formação e manutenção de tecidos; fonte energética, capazes de complementar e/ou substituir os carboidratos e lipídios; regulação do metabolismo, participando da síntese de secreções glandulares, desintoxicação, e síntese de uma gama de substâncias; ação imunológica, na formação de anticorpos e imunoglobulinas; equilíbrio ácido-básico, auxiliando no sistema de tamponamento; genética, na formação de nucleoproteínas (Hoffmann, 2020).

De acordo com Ramos (2019), o grão de soja com defeitos apresenta variação no teor de proteína bruta entre 32,38 e 34,17\%, sendo: fermentados 32,38; queimado 33,55; ardido 34,17. Segundo Ziegler et al. (2016), o teor de proteína bruta em grão de soja, armazenados a $18 \%$ de umidade e $32^{\circ} \mathrm{C}$, apresentou queda no nível de proteína bruta de $39 \%$ para $35,4 \%$. Além disso, o comprometimento da estrutura do grão leva a redução no teor de proteína bruta, resultantes da degradação de aminoácidos e peptídeos devido à degradação por processos metabólicos (Zimmer et al., 2014).

\subsection{Solubilidade da proteína}

De acordo com Ziegler et al. (2018), a solubilidade das proteínas é fruto de alterações no meio, principalmente temperatura e umidade, resultando em desnaturação. Ainda, verifica-se que a desnaturação em geral decresce a solubilidade das proteínas. A temperatura potencializa o aumento das taxas metabólicas do grão, e junto à umidade é o principal responsável na formação de grãos queimados, ardidos e fermentados. Especialmente em grãos ardidos e queimados, a elevada temperatura compromete o teor de massa, reduzindo a solubilidade da proteína (Wrigley et al, 2016).

Ramos (2019) ressalta que, o teor de proteína solúvel inclui-se dentre os parâmetros qualitativos de uma matéria prima, uma vez que a solubilidade da proteína é inversamente proporcional aos defeitos metabólicos do grão, determinante para sua aplicação em função de suas propriedades. Além disso, afirma que solubilidade proteica é reflexo da condição do grão, encontrando maiores valores em grãos sadios, seguido, dos fermentados, ardidos e queimados.

A estocagem é uma estratégica relevante a fim de suprir a demanda anual, entretanto, as condições, principalmente quanto à umidade e temperatura, devem ser analisadas criteriosamente, assim, armazenamento a $35^{\circ} \mathrm{C}$ e $15 \%$ de umidade, resultam em queda da solubilidade (Ziegler et al., 2018).

A desnaturação das proteínas altera sua estrutura e compromete sua funcionalidade biológica. Do âmbito nutricional, a desnaturação influência na digestibilidade, disponibilidade de aminoácidos e atividade enzimática devido a alteração em sua conformação, sendo evidenciado que o aumento de temperatura excessivo reduz os coeficientes de digestibilidade dos aminoácidos (Ribeiro, 2018).

\section{Considerações Finais}

A integridade e conservação das propriedades do grão de soja são determinantes para obtenção de produtos de 
qualidade. Primordialmente na alimentação animal, o avanço dos defeitos (fermentado, ardido, queimado), compromete negativamente o valor nutricional, interferindo no metabolismo digestível, principalmente na degradação de proteínas degradáveis no rúmen, bem como, no aproveitamento de volumosos para formação de proteína microbiana e na absorção de demais nutrientes presentes na luz intestinal.

Desta forma, em razão das alterações físico-químicas e nutricionais acarretados pelos defeitos do grão da soja, é indispensável por parte das indústrias a classificação criteriosa. Por fim, considerando que o uso de grão de soja com defeito onera qualitativamente a ração, não é recomendado sua utilização.

\section{Agradecimentos}

A Coordenação de Aperfeiçoamento de Pessoal de Nível Superior - Brasil (CAPES), ao Conselho Nacional de Desenvolvimento Científico e Tecnológico (CNPq), a Fundação Araucária de Apoio ao Desenvolvimento Científico e Tecnológico do Estado do Paraná e a Universidade Estadual de Maringá (UEM).

\section{Referências}

Alves, G. H., Paraginski, R. T., Lamas, N. S., Hoffmann, J. F., Vanier, N. L. \& Oliveira, M. (2017). Effects of Organic and Conventional Cropping Systems on Technological Properties and Phenolic Compounds of Freshly Harvested and Stored Rice. Journal of Food Science, 82 (10), $2276-2285$.

Dueñas, M., Hernandez, T., Robredo, S., Lamparski, G. \& Munoz, R. (2012). Bioactive Phenolic Compounds of Soybean (Glycine max cv. Merit): Modifications by Different Microbiological Fermentations. Polish Journal of Food and Nutrition Sciences, 62 (4), $241-250$.

Dürks, J. M., Botelho, F. M., Botelho, S. C. C., Ruffato, S. \& Hoscher, R. H. (2019). Perdas quantitativas e qualitativas em soja armazenada com aeração convencional e resfriamento artificial. Revista de Ciências Agroambientais, 17 (1), 31-39, 2019.

EMBRAPA. Estatística e Desempenho de produção. Central de Inteligência de Aves e Suínos. https://www.embrapa.br/suinos-e-aves/cias/estatisticas.

Freiria, G. H., Gonçalves, L. A., Gomes, G. R., Furlan, F. F., Lima, W. F. \& Prete, C. E. C. (2020). Produtividade, proteínas, compostos bioativos e minerais em grãos de soja tipo alimento em diferentes ambientes. Revista Brasileira de Ciências Agrárias (Agrária), 15 (2), 1-9.

Hirakuri, M. H., Lorini, I., França-Neto, J. B., Krzyzanowski, F. C., Henning, A. A., Henning, F. A., Mandarino, J. M. G., Oliveiro, M. A. \& Benassi, V. T. (2018). Análise de aspectos econômicos sobre a qualidade de grãos de soja no Brasil. Circular técnica 145. Embrapa Soja, 1-22.

Hoffmann, F. (2020). Efeito da relação proteína degradável no rúmen: proteína indegradável no rúmen e do tipo de volumoso na dieta de ruminantes. Dissertação de Mestrado. Universidade Tecnológica Federal do Paraná.

Instituto Brasileiro De Geografia $\quad \mathrm{E} \quad$ Estatística $\quad$ (IBGE). Resultados do 2017. https://censos.ibge.gov.br/agro/2017/templates/censo_agro/resultadosagro/pecuaria.html.

Japiassu, K. B. (2018). Biossíntese catalisada por Beauveria bassiana ATCC 7159 de um novo flavonóide metilglicosilado potencialmente antioxidante e antifúngico. Dissertação de Mestrado em Ciências Farmacêuticas. Universidade Federal de Goiás.

KozloskI, G. V. (2017). Bioquímica dos ruminantes. (3a ed.), Editora UFSM, 2017.

Mateus, R. G., Pereira, L. C., Jadoski, C. J., Guilherme, D. \& Alves, R. T. B. (2018). Composição químico-bromatológica de diferentes subprodutos da soja. Revista Brasileira de Tecnologia Aplicada nas Ciências Agrárias, 11 (1), 79-85.

Mendes, M. C., Pinho, R. G. V., Pinho, E. V. R. V. \& Faria, M. V. (2012). Comportamento de híbridos de milho inoculados com os fungos causadores do complexo grãos ardidos e associação com parâmetros químicos e bioquímicos. Ambiência, 8 (2), $275-292$.

Menezes, B. B., Lima, F. C. S., Junges, L., Gomes, E. N. O. \& Echeverria, D. M. S. (2017). Glicinina E B-Conglicinina Em Ruminantes. In: Anais Da X Mostra Científica Famez / UFMS.

Monteiro, C. P. \& Silva, S. L. (2019). Qualidade da carne de bovinos. Inclusão de óleos essenciais na dieta sobre o desempenho e qualidade da carne de bovinos terminados em confinamento. In: Anais IV Simpósio de Pós-Graduação em Zootecnia.

Lima Júnior, D. M., Monteiro, S. P. B., Rangel, A. H. N., Maciel, M. V., Oliveira, S. E. O. \& Freire, D. A. (2010). Fatores anti-nutricionais para ruminantes. Acta Veterinaria Brasilica, 4 (3),132-143.

Müller, L. R. (2018). Inclusão de fontes de lipídeos como estratégia econômica para terminação de bovinos nelore em confinamento. Dissertação de Mestrado, Universidade Estadual Paulista.

Pinto, R. S., Botelho, F. M., Botelho, S. C. C. \& Angeli, A. M. (2017). Qualidade de grãos de soja em diferentes épocas de colheita. Nativa, 5 (especial), $463-$ 470 .

Prete, A. C. L. (2019). Bioquímica metabólica aplicada à nutrição. Editora Senac. 
Research, Society and Development, v. 10, n. 2, e31110212561, 2021

(CC BY 4.0) | ISSN 2525-3409 | DOI: http://dx.doi.org/10.33448/rsd-v10i2.12561

Ramos, A. H. (2019). Implicações dos defeitos fermentado, ardido e queimado em grãos de soja no rendimento e na qualidade lipídica e proteica. Dissertação de Mestrado. Universidade Federal de Pelotas.

Santin, J. A., Reis, E. M., Matsumura, A. T. S. \& Moraes, M. G. (2004). Efeito do retardamento da colheita de milho na incidência de grãos ardidos e de fungos patogênicos. Revista Brasileira de Milho e Sorgo, 3 (2), 182-192.

Santin, J. A., Gutkoski, L. C., Eichelberger, L., Portella, J. A. \& Durigon, A. (2009). Qualidade microbiológica de grãos de milho armazenados em silos de alambrado e secados com ar natural forçado. Revista Brasileira de Milho e Sorgo, 8 (2), 131-144.

Rasera, G. B. \& Castro, R. J. S. (2020). Germinação de grãos: uma revisão sistemática de como os processos bioquímicos envolvidos afetam o conteúdo e o perfil de compostos fenólicos e suas propriedades antioxidantes. Brazilian Journal of Natural Sciences, 3 (1), 287-287.

Ribeiro, P. (2018). Avaliação da desnaturação de proteínas do farelo de soja durante os processos operacionais. Trabalho de Conclusão de Curso. Universidade Tecnológica Federal do Paraná.

Silva, F. M., Pedroza, M. M., Oliveira, L. R. A., Colen, A. G. N. \& Amaral, P. H. B. (2019). Rotas tecnológicas empregadas no aproveitamento de resíduos da indústria da soja. Revista Brasileira de Energias Renováveis, 8 (1), 326-363.

Souza, C. G., Moura, A. K. B., Silva, J. N. P., Soares, K. O., Silva, J. V. C. \& Vasconcelos, P. C. (2019). Fatores antinutricionais de importância na nutrição animal: Composição e função dos compostos secundários. PUBVET, 13 (5), 1-19.

Stech, M. R. \& Carvalho, M. R. B. (2019). Avaliação da composição centesimal e das atividades dos fatores antinutricionais em diferentes cultivares de soja. Boletim do Instituto de Pesca, 24 (especial), 139-145.

Wrigley, C., Corke, H., Seetharaman, K. \& Faubion, J. (2016). Encyclopedia of Food Grains. (2a ed.), Lisa Tickner.

Ziegler, V., Ferreira, C. D., Hoffmann, J. F., Oliveira, M. \& Elias, M. C. (2018). Effects of moisture and temperature during grain storage on the functional properties and isoflavone profile of soy protein concentrate. Food Chemistry, 242 (1), 37-44.

Ziegler, V., Vanier, N. L., Ferreira, C. D., Paraginski, R. T., Monks, J. L. F. \& Elias, M. C. (2016). Changes in the Bioactive Compounds Content of Soybean as a Function of Grain Moisture Content and Temperature during Long-Term Storage. Journal of Food Science, 81 (3), $762-768$.

Zimmer, S., Messmer, M., Haase, T., Piepho, H., Mindermann, A., Schulz, H., Habekuß, A., Ordon, F., Wilbois, K. \& Heß, J. (2014). Effects of soybean variety and Bradyrhizobium strains on yield, protein content and biological nitrogen fixation under cool growing conditions in 79 Germany. European Journal of Agronomy, 27 (6), 448-452. 